\title{
Simultaneous incentive contrast effects with alcoholic and nonalcoholic beverages as the discriminanda for reward magnitude
}

\author{
W. MILES COX \\ University of Minnesota, Morris, Minnesota 56267
}

\begin{abstract}
Alcoholic and nonalcoholic beverages consumed by rats prior to runway conditioning trials served as cues for reward magnitude. Learning under the alcoholic (but not the nonalcoholic) cue condition appeared to be state dependent. Under both conditions, a simple effect for reward magnitude occurred, but positive and negative incentive contrast effects occurred under only the alcoholic condition. The symmetrical contrast effects seem consistent with the view that alcohol enhances positive states rather than reduces negative ones.
\end{abstract}

The simultaneous incentive contrast paradigm involves training subjects to respond in the presence of two different stimulus cues, each of which is associated with a different value of a reward parameter. If, in the presence of the cue associated with the less valuable reward, subjects perform at a lower level than control subjects receiving only the less valuable reward, a negative incentive contrast effect is said to occur. Similarly, if, in the presence of the cue associated with the more valuable reward, subjects exceed the performance of control subjects receiving only the more valuable reward, a positive incentive contrast effect is said to occur. Negative contrast regularly occurs in simultaneous studies, while positive contrast generally fails to appear (see Cox, 1975).

A variety of discriminative cues have been employed in studies of simultaneous incentive contrast effects. With animal subjects, however, the cues most typically have been a black and a white runway. Characteristically, experimental animals receive a small food reward in one runway and a large food reward in the other runway; trials are administered in an intermixed fashion between the two runways; and speed of running in each runway is the measure of performance.

The present experiment also involved within-subjects runway conditioning for two magnitudes of a food reward, but the animals were always run in the same gray runway. For the experimental animals, the discriminative cues for the two reward magnitudes were alcoholic and nonalcoholic beverages consumed immediately before the conditioning trials. Prior research has indicated that centrally acting drugs readily serve as discriminanda in differential conditioning

Requests for reprints should be sent to W. Miles Cox, Division of Social Sciences, University of Minnesota, Morris, Minnesota 56267. experiments (see Overton, 1972). Animals can learn, for example, to make one correct response (e.g., a position turn in a T-maze) while drugged and a different correct responses (e.g., the opposite turn in a T-maze) while not drugged. Apparently, however, there have been no prior studies of simultaneous incentive contrast effects in which animals respond for one magnitude of reward while drugged and a different magnitude of reward while not drugged.

On the basis of prior studies of simultaneous incentive contrast effects, it was predicted that in the present experiment the sober animals would show a negative contrast effect but no positive contrast effect. There were, however, reasons to expect a different outcome with the inebriated animals. Thus, on the basis of the tension reduction hypothesis (Cappell, 1975), which states that tension and anxiety are reduced following alcohol ingestion, it could be reasoned that alcohol would reduce the frustration occasioned by reductions in reward (Amsel, 1958, 1962) and thereby attenuate or eliminate the negative incentive contrast effect. Conversely, on the basis of studies that show that alcohol enhances positive states rather than reduces negative ones (Connors \& Maistro, 1979; McCollam, Burish, Maisto, \& Sobell, 1980), it would be expected that alcohol would contribute to the elation resulting from upshifts in reward and, in turn, would foster the development of positive contrast. Since the present experiment provided a test for both positive contrast and negative contrast under both sober and inebriated conditions, it allowed us to compare these two views about the effects of alcohol.

\section{METHOD}

Subjects

The subjects were 40 female rats, Sprague-Dawley derivatives (Charles River Co., Wilmington, Mass.), and were approximately 100 days old at the beginning of training. 


\begin{abstract}
Apparatus
The apparatus was a straight runway that was painted flat gray and had clear Plexiglas ceilings. The interior was $11.5 \mathrm{~cm}$ in width and $154 \mathrm{~cm}$ in length, and the startbox, alley, and goalbox were 33,92 , and $29 \mathrm{~cm}$ long, respectively. Guillotine doors separated the startbox and the goalbox from the alley. Response latencies were measured with photoelectronic circuitry from the opening of the startbox door to a point $18 \mathrm{~cm}$ inside the goalbox, a total distance of $110 \mathrm{~cm}$. Inside the goalbox, a $1-\mathrm{W}$ lamp was affixed $1.5 \mathrm{~cm}$ from the top of the end wall. The food cup, consisting of a metal measuring teaspoon, extended into the goalbox from the end wall and rested on the floor.
\end{abstract}

\section{Procedure}

Upon receipt from the supplier, the subjects were housed in individual cages and were given $10 \mathrm{~g}$ of food each day until their weights had reached $83 \%$ of their ad-lib values. Thereafter, compensatory food was given each day to maintain the weights at $83 \%$ ad lib.

To facilitate the animals' consumption of the alcoholic and nonalcoholic solutions to which they were exposed prior to the conditioning trials each day, the solutions were made palatable and the animals were fluid deprived when they were exposed to them. This procedure has been followed in several of our prior studies (Cox \& Stainbrook, 1977; Kemble, Godding, \& Cox, Note 1). ${ }^{1}$ The fluid deprivation regimen, which allowed the animals 15-min access to fluid each day, was instituted 5 days prior to runway conditioning. Water was exposed for $15 \mathrm{~min}$ on the $1 \mathrm{st}$ day, and sucrose solution or sucrose solution containing $4.75 \%$ ethanol was exposed on the following 4 days, according to a counterbalanced arrangement (ABBA for half of the animals and $B A A B$ for the other half). The $10 \%$ sucrose solution contained $10 \mathrm{~g}$ of granulated cane sugar per $100 \mathrm{ml}$ of tap water, while the sucrose solution with alcohol contained $5 \mathrm{ml}$ of $95 \%$ ethanol per $95 \mathrm{ml}$ of the $10 \%$ sucrose solution. The fluids were always at room temperature when they were administered to the animals. On the 5 th day of fluid deprivation, the animals explored the runway for $5 \mathrm{~min}$ in groups of five animals each, and on the following day experimental training was initiated.

During training, the animals were given access to either the sucrose solution or the sucrose solution with alcohol in their home cages prior to their daily trials. Across days, all animals had equal exposure time to the two solutions, and the daily order in which they drank each solution was determined by a repetitive ABBABAAB arrangement. A squad of 10 animals was allowed to drink for $15 \mathrm{~min}$ and then was transported immediately to the experimental room.

Four groups of subjects were run. For the two experimental groups, the fluid consumed prior to the runway trials served as the cue for the magnitude of food reward in the runway. One experimental group (nonalcoholic-large/alcoholic-small) received 22 45-mg Noyes food pellets (large reward) in the runway on the days when it had drunk the sucrose solution and one 45-mg Noyes pellet (small reward) on the days when it had drunk the sucrose solution with alcohol. The other experimental group (nonalcoholicsmall/alcoholic-large) received the small reward after having drunk the sucrose solution and the large reward after having drunk the sucrose solution with alcohol. One of the control groups (nonalcoholic-large/alcoholic-large) received the large reward both on days when it had drunk the sucrose solution and on days when it had drunk the sucrose solution with alcohol. Likewise, the second control group (nonalcoholic-small/alcoholic-small) always received the small food reward in the runway, regardless of which solution it had drunk prior to the runway trials.

Each animal was placed into the runway facing away from the startbox door, and, as soon as it had oriented toward the door, the door was opened to permit traversal of the alley. When the animal had entered the goalbox, the goalbox door was closed to prevent reentry of the alley. All animals were confined in the goal- box for $30 \mathrm{sec}$ or until they had completely consumed the reward, whichever came last, before being returned to the carrying cage to await the next trial. One trial was administered on the first 4 days of training, and four daily trials were administered on the next 24 days, for a total of 100 trials. An intertrial interval of approximately 15 min resulted.

When each squad's daily trials had been completed, the animals were weighed, returned to their home cages, and provided with the appropriate amount of food to compensate for any loss in weight below $83 \%$ ad lib.

\section{RESULTS}

Prior to analysis, all running times were converted into speeds $(\mathrm{cm} / \mathrm{sec})$. To reduce variability in the data, the reciprocals of each subject's four daily trials were averaged, and moving trial blocks were computed. ${ }^{2}$ Start, run, and goal speeds are very similar to total speeds, and only the latter are presented here.

Total speeds of the two control and two differential groups under the nonalcoholic cue condition are shown in Figure 1. Inspection of Figure 1 indicates that all four groups showed considerable improvement in speeds during the course of training and appear to have stabilized by the end of training. Analysis of variance confirmed that there was a highly significant effect for trials $[F(11,396)=130.12, p<$ $.001]$, as well as a significant groups $\times$ trials interaction $[F(33,396)=1.59, p=.02]$, but no main effect for groups $[F(3,36)=2.01, p=.13]$. The groups $\times$ trials interaction reflects, in part, the fact that even though the control group receiving large reward ran more rapidly throughout training than the control group receiving small reward, this difference was significant only on Trial Blocks $1-5[F(1,18)=7.05$, $\mathrm{p}<.02$ ]. In addition, on Trial Blocks $1-4$, the differential group receiving small reward ran more rapidly than the differential group receiving large reward $[F(1,18)=17.70, p=.001]$, but the speeds of these

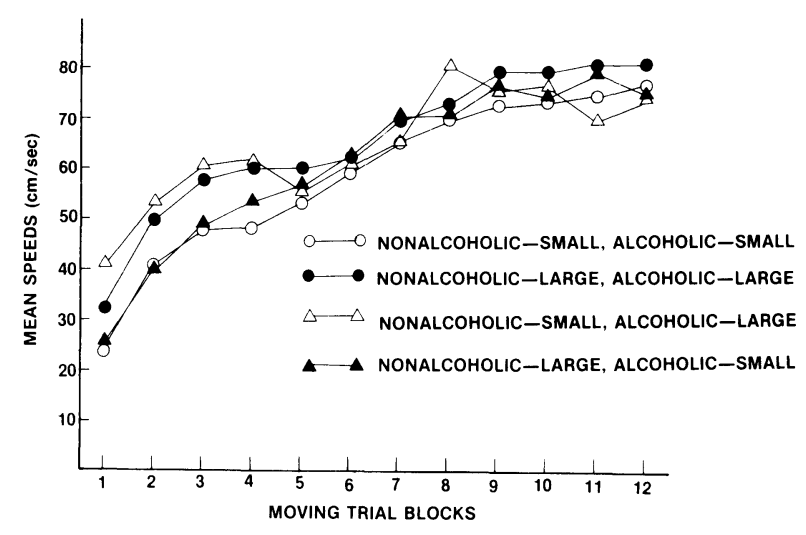

Figure 1. Mean total speeds of the four groups under the nonalcoholic cue condition as a function of moving trial blocks. 
groups converged thereafter and remained together until the conclusion of training.

Total speeds of the four groups under the alcoholic cue condition are shown in Figure 2. Inspection indicates that under this cue condition the four groups also showed considerable improvement in speed during the first half of training. Analysis of variance indicated highly significant effects for trials $[\mathrm{F}(11,396)$ $=59.47, \mathrm{p}<.001]$, groups $[\mathrm{F}(3,36)=5.04, \mathrm{p}=.005]$, and the groups $\times$ trials interaction $[F(33,396)=8.05$, $p<.001]$. The latter two effects reflect, in part, the faster running by the control group receiving large reward than by the control group receiving small reward during the first half of training and the convergence of these two groups during the latter part of training. A separate statistical analysis of the speeds of the two control groups on Trial Blocks 1-7 indicated a significant groups effect $[F(1,18)=6.79$, $\mathrm{p}<.02$ ]. It should also be noted that, graphically, the differential group receiving small reward ran more rapidly on the initial trial blocks than the differential group receiving large reward. This initial reversal in the expected effect for reward magnitude was also observed among the differential groups when they were trained under the nonalcoholic condition.

The most striking group difference shown in Figure 2, however, is the clear divergence of the two experimental groups from their respective controls during the latter part of training. The experimental group receiving small reward ran more slowly than the control group receiving small reward (negative incentive contrast effect), and the experimental group receiving large reward ran more rapidly than the control group receiving large reward (positive incentive contrast effect). The negative contrast effect observed on Trial Blocks 7-12 is statistically reliable, as indicated by a highly significant effect for groups $[F(1,18)$

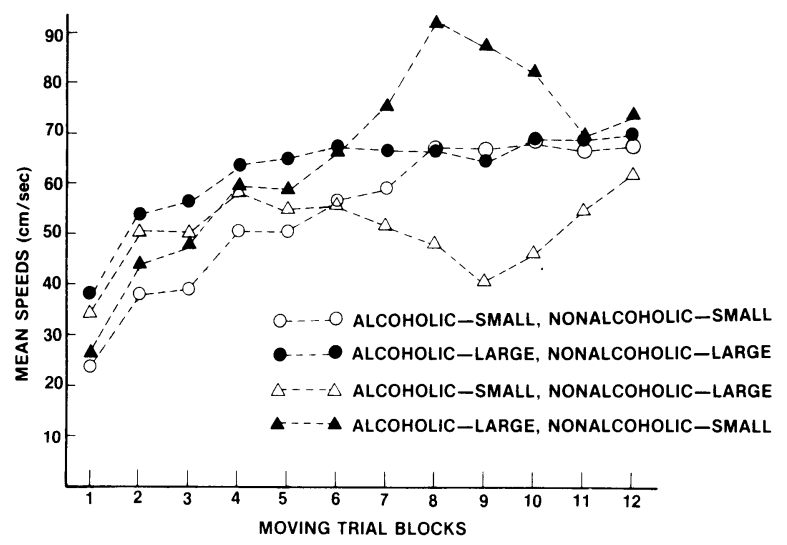

Figure 2. Mean total speeds of the four groups under the alcoholic cue condition as a function of moving trial blocks.
$=9.79, \mathrm{p}=.006]$, for trials $[\mathrm{F}(5,90)=9.40, \mathrm{p}<.001]$, and the groups $\times$ trials interaction $[F(5,90)=11.81$, $\mathrm{p}<.001]$. Likewise, the positive contrast effect observed on Trial Blocks 7-10 is statistically reliable, as indicated by a highly significant effect for groups $[F(1,18)=25.25, p<.001]$, for trials $[F(3,54)=7.76$, $\mathrm{p}<.001]$, and the groups $\times$ trials interaction $[\mathrm{F}(3,54)$ $=10.47, \mathrm{p}<.001]$. Also noteworthy from Figure 2 is the symmetry of the contrast effects. Both the negative contrast effect and the positive contrast effect first appeared on Trial Block 7; the "undershooting" and "overshooting" quickly reached their maximum levels; and then the animals more gradually returned to the levels of the two control groups.

Finally, it should be noted that all four groups responded differently under the two cue conditions. The control group receiving small reward ran more slowly under the alcoholic condition $[F(1,9)=5.59$, $p<.05$ ], and the control group receiving large reward ran more slowly under the alcoholic condition on Trial Blocks 7-12 [F(1,9) $=12.91, p=.006]$. Group Nonalcoholic-Large/Alcoholic-Small also ran more slowly under the alcoholic condition later in training as negative contrast developed. Analysis indicated a significant effect for conditions $[\mathrm{F}(1,9)=19.91$, $\mathrm{p}=.002]$ and a significant conditions $\times$ trials interaction $[F(11,99)=16.48, p<.001]$. Group Nonalcoholic-Small/Alcoholic-Large, on the other hand, ran more slowly under the alcoholic condition early in training but more rapidly under this condition as training progressed and positive contrast developed. Analysis here indicated a significant conditions $\times$ trials interaction $[F(11,99)=6.73, p<.001]$. In summary, these group differences, especially the slower performance by the control groups under the alcoholic condition, indicate that alcohol depressed running speeds, probably as a result of its ataxic effects. Nevertheless, as the previous analyses indicated, the depression was not sufficient to obliterate reward-magnitude effects and contrast effects.

\section{DISCUSSION}

The animals in the present experiment readily acquired the instrumental running response. Typical, negatively accelerated conditioning curves were observed among all four groups. There was, in addition, a simple effect for reward magnitude. Under both the alcoholic and nonalcoholic cue conditions, the control group receiving large reward ran more rapidly than the control group receiving small reward.

Responsiveness to the large and small rewards by the two differential groups, on the other hand, was more complex and was quite different under the two cue conditions. Under the nonalcoholic condition, after the initial trial blocks the two differential groups ran at comparable speeds; they showed no effect for 
reward magnitude and no contrast effects. Their performance while sober, therefore, was not meaningfully affected by the reward magnitude that they received under either of the cue conditions. Under the alcoholic cue condition, on the other hand, the differential group receiving large reward ran more rapidly than the differential group receiving small reward. In addition, the differential group receiving large reward ran more rapidly than the control group receiving large reward (positive contrast), and the differential group receiving small reward ran more slowly than the control group receiving small reward (negative contrast). Thus, under the alcoholic cue condition, the differential groups were affected both by the reward magnitude that they received under this cue condition and by the reward magnitude that they received under the nonalcoholic cue condition.

Since the running speeds of the differential animals were influenced by the reward magnitude that they received under the alcoholic cue condition only while they were inebriated, it appears that learning under this cue condition may have been dissociative or state dependent. Since, however, the reward magnitude received under the nonalcoholic cue condition did influence the running speeds of the differential animals while they were inebriated, the possible statedependent effects were asymmetrical. This finding is consistent with that of several previous animal studies (Barnhart \& Abbott, 1967; Berger \& Stein, 1969) and human studies (Goodwin, Powell, Bremer, Hoine, \& Stern, 1969; Storm \& Caird, 1967) that have identified asymmetrical dissociative effects in which learning transfers from the nondrugged to the drugged state but not vice versa. Furthermore, this phenomenon is analogous to the alcoholic "blackout," in which the sober alcoholic is amnesic for events occurring while he or she was intoxicated but is sometimes able to recall them during subsequent drinking (see Goodwin, Crane, \& Guze, 1969; Storm \& Smart, 1965). The similarity raises the possibility of developing an animal model for studying the parameters of the alcoholic blackout.

Another aspect of the present data that is of special interest is the nature of the contrast effects that occurred among the inebriated animals. The negative contrast effect observed among the differential animals receiving small reward was quite pronounced and was similar to the simultaneous negative contrast that has previously been observed in differential conditioning studies (see Cox, 1975). Thus, there is no indication that alcohol attenuated the negative contrast, and hence no support is gained for the tension reduction hypothesis of alcohol consumption. Other studies (Denenberg, Pawlowski, \& Zarrow, 1961; Taylor, Lehr, Berger, \& Terry, 1968) have also found that rats do not show less vigorous behavioral indices of frustration when intoxicated than when sober.
In fact, among human subjects, alcohol has sometimes been found to exacerbate negative emotional states (e.g., Nathan \& O'Brien, 1971; Okulitch \& Marlatt, 1972; Warren \& Raynes, 1972; Williams, 1966).

The positive contrast effect that occurred among the inebriated animals receiving differential conditioning was also quite pronounced, and it appears to be the counterpart of the negative contrast effect. Yet, positive incentive contrast has seldom been obtained in "standard" runway situations involving immediate reward. However, with successive shifts in magnitude of delayed reward, several studies have resulted in positive contrast (e.g., Mellgren, 1971, 1972). Experimenters employing delayed reward procedures argue that positive contrast generally fails to appear because upshifted animals reach a "ceiling" that makes it impossible for them to run faster than do large-reward control animals. Since delayed reward suppresses performance, it presumably allows positive contrast to be manifested. ${ }^{3}$ Although alcohol did generally depress running speeds in the present experiment, the ceiling effect hypothesis cannot account for the observed positive contrast, since the differential animals receiving large reward while intoxicated ran more rapidly than animals trained under any of the other conditions, including the ones combining large reward with the nonalcoholic cue. Thus, the present results point to another special set of circumstances that is an exception to the general rule that positive contrast does not occur.

The positive contrast effect apparently was engendered by alcohol, even though alcohol did not eliminate a ceiling effect. It seems more likely that the alcohol contributed to the differential rats' "elation" following upshifts in reward or in some other way enhanced the attractiveness of the large reward and the rats' responsiveness to it. Because of the apparent facilitative effect by alcohol on the positive contrast effect and its apparent lack of effect on the negative contrast effect, the outcome of the present experiment seems, on balance, to be more consistent with the view that alcohol enhances positive states rather than with the view that it alleviates negative ones.

\section{REFERENCE NOTE}

1. Kemble, E. D., Godding, P. R., \& Cox, W. M. The effects of septal lesions on self-administration of ethanol in rats. Manuscript submitted for publication, 1981.

\section{REFERENCES}

Amsel, A. The role of frustrative nonreward in noncontinuous reward situations. Psychological Bulletin, 1958, 55, 102-119. Amsel, A. Frustrative nonreward in partial reinforcement and discrimination learning: Some recent history and a theoretical extension. Psychological Review, 1962, 69, 306-328. 
Barnhart, S. S., \& Aвbott, D. W. Dissociation of learning and meprobamate. Psychological Reports, 1967, 20, 520-522.

Berger, B., \& Stein, L. Asymmetrical dissociation of learning between scopolamine and Wy 4036, a new benzodiazepine tranquilizer. Psychopharmacologia, 1969, 14, 351-358.

BLACK, R. W. Reward variables in instrumental conditioning: A theory. In G. H. Bower (Ed.), The psychology of learning and motivation (Vol. 10). New York: Academic Press, 1976.

Cappell, H. An evaluation of tension models of alcohol consumption. In R. J. Gibbins, Y. Israel, H. Kalant, R. E. Popham, W. Schmidt, \& R. G. Smart (Eds.), Research advances in alcohol and drug problems (Vol. 2). New York: Wiley, 1975.

Connors, G. J., \& Maisto, S. A. Effects of alcohol, instructions, and consumption rate on affect and physiological sensations. Psychopharmacology, 1979, 62, 261-266.

Cox, W. M. A review of recent incentive contrast studies involving discrete-trial procedures. Psychological Record, 1975, 25, 373-393.

Cox, W. M., \& Stainbrook, G. L. Stress-induced alcohol consumption: A new paradigm. British Journal on Alcohol and Alcoholism, 1977, 12, 23-29.

Denenberg, V. H., Pawlowski, A. A., \& Zarrow, M. X. Prolonged alcohol consumption in the rat. I. Acquisition and extinction of a bar-pressing response. Quarterly Journal of Studies on Alcohol, 1961, 22, 14.

Goodwin, D. W., Crane, J. B., \& Guze, S. B. Phenomenological aspects of the alcoholic "blackout." British Journal of Psychiatry, 1969, 115, 1033-1038.

Goodwin, D. W., Powell, B., Bremer, D., Hoine, H., \& StERN, J. Alcohol and recall: State dependent effects in man. Science, 1969, 163, 1358-1360.

McCollam, J. B., Burish, T. A., Maisto, S. A., \& Sobell, M. B. Alcohol's effects on physiological arousal and selfreported affect and sensations. Journal of Abnormal Psychology, 1980, 89, 224-233.

Mellgren, R. L. Positive contrast in the rat as a function of the number of preshift trials in the runway. Journal of Comparative and Physiological Psychology, 1971, 77, 329-336.

Mellgren, R. L. Positive and negative contrast effects using delayed reinforcement. Learning and Motivation, 1972, 3, 185-193.

Nathan, P. E., \& O'Brien, J. S. An experimental analysis of the behavior of alcoholics and nonalcoholics during prolonged experimental drinking: A necessary precursor of behavior therapy? Behavior Therapy, 1971, 2, 455-476.

OKulitch, P. V., \& MarlatT, G. A. Effects of varied extinction conditions with alcoholic and social drinkers. Journal of $A b$ normal Psychology, 1972, 79, 303-309.

Overton, D. A. State-dependent learning produced by alcohol and its relevance to alcoholism. In B. Kissin \& H. Begleiter
(Eds.), The biology of alcoholism: Physiology and behavior (Vol. 2). New York: Plenum Press, 1972.

Storm, T., \& CaIrd, W. K. The effects of alcohol on serial verbal learning in chronic alcoholics. Psychonomic Science, 1967, 9. 43-44.

Storm, T., \& Smart, R. G. Dissociation: A possible explanation of some features of alcoholism, and implications for its treatment. Quarterly Journal of Studies on Alcohol, 1965, 26, 111-115.

Taylor, A., Lehr, R., Berger, D. F., \& Terry, C. A. Effects of alcohol on the partial reinforcement effect. Psychonomic Science, 1968, 11, 371.

Warren, G. H., \& Raynes, A. E. Mood changes during three conditions of alcohol intake. Quarterly Journal of Studies on Alcohol, 1972, 33, 979-989.

Williams, A. F. Social drinking, anxiety, and depression. Journal of Personality and Social Psychology, 1966, 3, 689-693.

\section{NOTES}

1. Our previous studies have shown that, under these conditions, thirsty rats consume, on the average, approximately $15-20 \mathrm{ml}$ of the alcoholic solution in $15 \mathrm{~min}$ and approximately $20-25 \mathrm{ml}$ of the nonalcoholic solution.

2. Basically, the moving trial blocks (MTBs) were computed by averaging the trials for 3 successive days of training. However, due to the difference in the order in which the animals were trained under the two cue conditions (i.e., on the 1st day of training, all animals drank the alcoholic solution, on the 2nd day of training, all animals drank the nonalcoholic solution, etc.), the MTBs were computed somewhat differently for the two conditions. Specifically, for the alcoholic cue condition, MTB 1 is the average of trials on Days 1, 2, and 3 under that condition; MTB 2 is the average of trials on Days 2, 3, and 4 under that condition; ... and MTB 12 is the average of trials on Days 12 and 13 under that condition. For the nonalcoholic cue condition, MTB 1 is the average of trials on Day 1 under that condition; MTB 2 is the average of trials on Days 1, 2, and 3 under that condition; MTB 3 is the average of trials on Days 2, 3, and 4 under that condition; ... and MTB 12 is the average of trials on Days 11 and 12 under that condition.

3. Black (1976, pp. 227-28) has offered an alternative explanation for why positive contrast occurs with delayed reward. It is also worth noting that the symmetrical contrast effects that occurred in the present experiment are remarkably similar to the theoretical curves generated by Black $(1976$, p. 228$)$ to predict symmetrical contrast effects with delayed reward.

(Manuscript received November 10, 1980; accepted for publication August 4, 1981.) 